\title{
Inequities in utilization of reproductive and maternal health services in Ethiopia
}

\author{
Firew Tekle Bobo ${ }^{1 *}$, Elias Ali Yesuf ${ }^{2,3}$ and Mirkuzie Woldie ${ }^{2}$
}

\begin{abstract}
Background: Disparities in health services utilization within and between regional states of countries with diverse socio-cultural and economic conditions such as Ethiopia is a frequent encounter. Understanding and taking measures to address unnecessary and avoidable differences in the use of reproductive and maternal health services is a key concern in Ethiopia. The aim of the study was to examine degree of equity in reproductive and maternal health services utilization in Ethiopia.

Method: Data from Ethiopia demographic health survey 2014 was analyzed. We assessed inequities in utilization of modern contraceptive methods, antenatal care, facility based delivery and postnatal checkup. Four standard equity measurement methods were used; equity gaps, rate-ratios, concertation curve and concentration index.

Results: Inequities in service utilization were exhibited favoring women in developed regions, urban residents, most educated and the wealthy. Antenatal care by skilled provider was three times higher among women with post-secondary education than mothers with no education. Women in the highest wealth quantile had about 12 times higher skilled birth attendance than those in lowest wealth quantile. The rate of postnatal care use among urban resident was about 6 times that of women in rural area. Use of modern contraceptive methods was more equitably utilized service while, birth at health facility was less equitable across all economic levels, favoring the wealthy.

Conclusion: Considerable inequity between and within regions of Ethiopia in the use of maternal health services was demonstrated. Strategically targeting social determinants of health with special emphasis to women education and economic empowerment will substantially contribute for altering the current situation favorably.
\end{abstract}

Keywords: Inequity, Modern contraceptive, Antenatal care, Postnatal care, Birth in the facility, Ethiopia

\section{Background}

Equity in the health sector has long been regarded as an important objective of the health system $[1,2]$. The poor tend to suffer greater rates of morbidity and mortality than do the rich. Despite the fact having higher level need for health services, they often utilize less than the rich $[2,3]$.

In developing countries, maternal health service utilization has improved over a time. However, many studies demonstrate the presence of significant inequalities based on urban/rural, education, socioeconomic and regional differences [4-6].

Use of modern contraceptive methods, antenatal care (ANC), skilled birth attendance and postnatal care

\footnotetext{
*Correspondence: free11messi@gmail.com

${ }^{1}$ Department of Public Health, College of Health sciences; Wollega University,

Nekemte, Ethiopia

Full list of author information is available at the end of the article
}

(PNC) are among the key maternal health interventions to have made undeniable differences in reducing maternal mortality worldwide $[7,8]$.

However, there is a limited use of those key interventions in developing countries, and are reported to have variations among population groups $[8,9]$. Health status in Ethiopia has dramatic improvements in recent decades [10-12]. The gains have been as a result of improvements in utilization of health care services amongst disadvantaged groups, particularly those living in rural areas $[2,13]$. Despite this progress, substantial inequalities still exist in health outcomes based on differences in economic status, education, place of residence and sex [14].

Disparities in reproductive and maternal health service utilization can be attributed to limitations in supply side associated to access of the service, quality of the service 
and affordability of the services [11, 15]. Accessibility of services in Ghana was largely observed favoring women residing in urban area than rural area, best performing region than the worst, highest wealth quantile than the lowest and at least secondary education than those with no formal education [16].

Limitations to the demand side can similarly affect utilization of maternal health services, and may operate at the individual, household and community levels. Factors at the individual level may include, age, income, education, culture and women's autonomy which could all largely contribute to women's capability to seek care $[3,5,9,17]$.

In Ethiopian context, both supply and demand sides significantly contribute to differences in maternal health service utilization. Major factors making things difficult for Ethiopian women to seek services may include indirect cost factors, cultural barriers, transport, perceived quality of care and autonomy demanding urgent interventions $[15,18]$.

Accelerated Expansion of Primary Health Care Coverage through health posts, is one of the initiatives undertaken by Ethiopian federal ministry of health to deliver preventive maternal and child health interventions mainly to the rural and impoverished parts of the population [19]. The country recently devised a new 5-year plan for the health sector, and among the transformation agendas quality and equity of services is the priority [14]. Hence, stressing the importance of recognizing where the country stands in terms of equity in the use of maternal health services.

Up until now the focus has been on improving access, coverage, health infrastructure and provision of quality service $[20,21]$. Therefore, in order to address the underprivileged, it is crucial to investigate the extent of inequalities in utilization of reproductive and maternal health services. The objective of the study was to examine and measure inequalities in utilization of reproductive and maternal health services based on four socioeconomic stratifiers, administrative regions, urban/ rural, education and economic status.

\section{Methods}

\section{Country profile}

Ethiopia is the second most populous country in Africa. According to the 2007 population and housing census projection, the total population is estimated to be 90 million by the year of 2015. The rural part of the country accounts for $84 \%$ of the Population [22]. The country is comprised of nine Regional States: Tigray, Amhara, Oromia, Southern Nation Nationalities and Peoples Region (SNNPR), Afar, Somali, and Harari; and two City Administrations council of Dire Dawa and Addis Ababa. Tigray, Amhara, Oromia and SNNPR are richer regions, while Afar, Somali and Harari are nomadic regions predominantly. Benishangul- Gumuz and Gambella are among the poorer regions in the country [23]. In terms of education, nowadays the net primary school enrolment (Grade 1-6) has reached 99\% [14].

Currently, Ethiopia has one of world's fastest growing economy. The economy has grown rapidly registering $10.9 \%$ GDP annual average growth rate over the past decade (2003/4 -2013/14). More than a decade ago, the country suffered from one of the highest poverty rates in the world, with majority of the population living below the international poverty line of $\$ 1.25$ purchasing power parity (PPP) a day [24]. This poverty rate has dramatically reduced from $56 \%$ in 2000 to $29 \%$ in 2012 [24]. The county's health care financing is highly dependent on donors (with almost $50 \%$ of total health expenditure), followed by households (34\%) in forms of out-of-pocket expenditure at the point of care [25].

Ethiopia has a three-tier health care delivery system. The first level is a Woreda/District health system comprising a primary hospital, health centers and their satellite Health Posts. The first two for the most part are engaged in curative and preventive health services, while health posts are front-runners in provision of preventive health services with a special attention to maternal and child health. The second level in the tier is a General Hospital and the third is Specialized Hospital, both exclusively focusing on curative health services. In 2015, there were a total of 311 hospitals (private included), 3547 health centers and 16,440 health posts available in the country [14].

\section{Data sources}

The study used data from 2014 Ethiopian demographic health survey for analysis. The survey was employed based on 2007 population and housing census of Ethiopia [22]. The survey included all 11 regions found in the country. All women of reproductive age (1549 years) residing in the selected households were eligible for the survey. The sample was pulled in two stages. In the first stage, 305 sampling units were drawn with a probability proportional to the region's size. Then, 30 households per cluster were selected through equal probability systematic selection technique. Finally, 8070 women of reproductive age group were interviewed out of the targeted 9150 eligible women.

\section{Study variable and definition}

The variables under this study are described under Table 1

\section{Wealth index}

Wealth index in the survey was computed using household asset data through principal component analysis. Wealth index is used as an indicator of level of wealth 
Table 1 Definition of reproductive and maternal health service indicators used in the study, 2014 Ethiopia

\begin{tabular}{ll}
\hline Maternal health services & Definition \\
\hline $\begin{array}{l}\text { Use of modern } \\
\text { contraceptive methods }\end{array}$ & $\begin{array}{l}\text { Percentage of currently married women age } \\
15-49 \text { utilizing modern contraceptive method }\end{array}$ \\
$\begin{array}{l}\text { Antenatal care by skilled } \\
\text { provider }\end{array}$ & $\begin{array}{l}\text { Percentage of women age 15-49 who had a } \\
\text { live birth in the } 5 \text { years preceding the survey } \\
\text { that received antenatal care from physicians, } \\
\text { nurses or midwives at least once }\end{array}$ \\
Skilled birth attendance & $\begin{array}{l}\text { Percentage of births assisted by physicians, } \\
\text { nurses, midwives or auxiliary midwives }\end{array}$ \\
Birth at health facility & $\begin{array}{l}\text { Percentage of live births in the 5 years } \\
\text { preceding the survey delivered in a health } \\
\text { facility (private or public) }\end{array}$ \\
& $\begin{array}{l}\text { Percentage of women age 15-49, with a live } \\
\text { birth in the 2 years preceding the survey who } \\
\text { received a postnatal checkup in the first 2 } \\
\text { days after giving birth }\end{array}$
\end{tabular}

that is in line with income and expenditure measures. The wealth index in the survey was created in three steps. First, wealth scores were calculated using indicators common for both urban and rural areas. In the second step, using indicators specific to household's in urban and rural areas separate factor scores were produced. Then in the third stage, separate area specific factor scores were combined to produce a nationally applicable wealth index by adjusting scores specific to the areas [26].

\section{Levels of education}

Educational status of women in the survey was categorized under four standard levels. Under the first category, women with no formal education labeled as no education. Women having (grade 1-8) formal education were categorized under primary level education. The third category includes, women having formal education of grade 9-12 considered as secondary level educated. Women receiving more than secondary education, those joining higher education and technical-professional education were labeled as more than secondary level in the survey [23].

\section{Urban/rural}

Urban areas include all capitals of administrative regions, zones and woredas. Areas with at least 1000 people primarily engaged in non-agricultural activities and/or localities declared as urban area by administrative officials. Rural areas are all areas which are not urban areas [27].

\section{Skilled provider}

Skilled health service providers includes doctor, nurse, midwife, and auxiliary nurse/midwife. Health extension workers are not considered as health professionals, but they are mainly involved in provision of promotive and preventive health services. Traditional birth attendants are birth attendants without any formal education background in service provision [28].

\section{Data analysis}

Several methods are available to evaluate equity in healthcare utilization. Equity for each reproductive and maternal health services were estimated using four standard equity measures - equity gaps, equity ratios, concentration curves and concentration indices $[28,29]$. The absolute percentage point difference in service coverage between the richest and poorest groups is used to show equity gaps. The equity ratio is calculated by dividing service coverage in the top wealth quintile by that in the bottom. The concentration curve plots the cumulative percentage of the population, ranked by wealth, beginning with the poorest, and ending with the richest ( $\mathrm{x}$-axis) against the cumulative percentage of the health service utilization (y-axis).

Concentration index (CI) is two times the area between the line of equality and the concentration curve. The index takes a value between -1 and $+1 ; 0$ index indicates presence of equality in utilization of the health variable. If socioeconomic inequalities exist, it can be seen in one of the two forms, the first and the most common is when there is uneven concentration of favorable health variable (access and utilization of health services) among the rich, in which case the concertation index takes on a positive value. The second is when the concentration index assumes negative value, which implies disproportionate concentration of health variable among the poor (commonly mortality and morbidity). When the concentration index takes on positive value the line on concentration curve will be below the equality line and vice versa [19-22]. The concentration index for $t=1, \ldots, T$ groups is easily computed in a spreadsheet program using the following formula [29-32]:

$$
C=\left(p_{1} L_{2}-p_{2} L_{1}\right)+\left(p_{2} L_{3}-p_{3} L_{2}\right)+\ldots+\left(p_{T-1} L_{T}-p_{T} L_{T-1}\right)
$$

where $p_{T}$ is the cumulative percentage of the sample ranked by economic status in group t, and $L_{T}$ is the corresponding concentration curve ordinate. Data was analyzed using STATA 13.0 and Microsoft Excel worksheet.

\section{Results}

Equity of reproductive and maternal health services were assessed in terms of four socio-economic determinants; wealth quintile, maternal education, administrative region and place of residence. The use of reproductive and maternal health indicators is presented in Table 2. 
Table 2 Utilization of major reproductive and maternal health services according to socio-determinants, Ethiopia 2014

\begin{tabular}{|c|c|c|c|c|c|c|c|c|c|c|}
\hline \multirow[t]{2}{*}{ Background characteristics } & \multicolumn{2}{|c|}{$\begin{array}{l}\text { Use of modern } \\
\text { contraceptive }\end{array}$} & \multicolumn{2}{|c|}{$\begin{array}{l}\text { Antenatal care by skilled } \\
\text { provider }\end{array}$} & \multicolumn{2}{|c|}{$\begin{array}{l}\text { Birth at health } \\
\text { facility }\end{array}$} & \multicolumn{2}{|c|}{$\begin{array}{l}\text { Skilled birth } \\
\text { attendance }\end{array}$} & \multicolumn{2}{|c|}{ Postnatal care } \\
\hline & Number & $\%$ & Number & $\%$ & Number & $\%$ & Number & $\%$ & Number & $\%$ \\
\hline \multicolumn{11}{|l|}{ Residence } \\
\hline Urban & 882 & 55.6 & 521 & 80.3 & 681 & 58.5 & 681 & 58.4 & 260 & 47.8 \\
\hline Rural & 4263 & 37.2 & 3157 & 34.8 & 4634 & 10.2 & 4634 & 9.1 & 1607 & 7.5 \\
\hline \multicolumn{11}{|l|}{ Regions } \\
\hline Tigray & 316 & 29.6 & 227 & 68.7 & 333 & 26.7 & 333 & 26.2 & 129 & 23.5 \\
\hline Affar & 56 & 13.7 & 39 & 31.0 & 64 & 9.9 & 64 & 10.0 & 22 & 8.0 \\
\hline Amhara & 1240 & 48.0 & 837 & 46.2 & 1120 & 12.0 & 1120 & 11.7 & 396 & 8.9 \\
\hline Oromiya & 2046 & 39.1 & 1471 & 32.7 & 2215 & 13.3 & 2215 & 13.1 & 784 & 10.9 \\
\hline Somali & 104 & 1.6 & 98 & 19.1 & 188 & 15.9 & 188 & 15.3 & 62 & 3.7 \\
\hline Benishangul-Gumuz & 54 & 38.8 & 39 & 38.8 & 59 & 21.0 & 59 & 16.3 & 22 & 19.8 \\
\hline SNNP & 1077 & 39.2 & 819 & 39.0 & 1151 & 14.9 & 1151 & 11.7 & 379 & 11.1 \\
\hline Gambela & 30 & 50.4 & 19 & 54.2 & 25 & 31.9 & 25 & 29.1 & 8 & 15.8 \\
\hline Harari & 14 & 42.9 & 9 & 69.7 & 12 & 45.3 & 12 & 45.5 & 5 & 39.3 \\
\hline Addis Ababa & 184 & 57.4 & 103 & 94.2 & 125 & 86.5 & 125 & 86.1 & 53 & 70.1 \\
\hline Dire Dawa & 22 & 34.6 & 15 & 78.4 & 22 & 59.2 & 22 & 59.2 & 8 & 49.3 \\
\hline \multicolumn{11}{|l|}{ Education } \\
\hline No education & 3121 & 34.6 & 2302 & 32.0 & 3452 & 8.8 & 3581 & 7.5 & 1137 & 8.1 \\
\hline Primary & 1586 & 46.0 & 1137 & 50.5 & 1582 & 22.5 & 1542 & 21.0 & 597 & 15.0 \\
\hline Secondary & 282 & 58.9 & 168 & 81.9 & 194 & 69.0 & 170 & 69.4 & 85 & 42.0 \\
\hline More than secondary & 156 & 64.7 & 71 & 96.3 & 87 & 91.7 & 77 & 90.7 & 48 & 59.9 \\
\hline \multicolumn{11}{|l|}{ Economic status } \\
\hline Lowest & 1001 & 27.1 & 836 & 23.7 & 1276 & 5.1 & 1276 & 4.5 & 456 & 3.4 \\
\hline Second & 1046 & 36.3 & 778 & 29.3 & 1146 & 6.4 & 1146 & 5.5 & 365 & 4.5 \\
\hline Middle & 1009 & 37.3 & 726 & 40.6 & 1103 & 11.0 & 1103 & 9.1 & 383 & 12.7 \\
\hline Fourth & 970 & 46.3 & 680 & 42.2 & 961 & 15.1 & 961 & 14.5 & 340 & 9.9 \\
\hline Highest & 1119 & 53.6 & 657 & 77.3 & 829 & 56.5 & 829 & 55.6 & 325 & 40.6 \\
\hline Overall & 5245 & 40.4 & 3678 & 41.2 & 5315 & 16.4 & 5315 & 15.5 & 1868 & 13.2 \\
\hline
\end{tabular}

Source of data: Ethiopia DHS 2014

\section{Use of modern contraceptive methods}

There was no significant difference in use of contraceptive methods among women in the nine administrative regions of the country. However, Somali (1.6\%) and Afar (13.7) were the two regional states utilizing the services at lower rate. Modern contraceptive use among currently married women living in urban areas is 1.5 times higher than in rural area. The prevalence among mothers with no education is about two times less than those with more than secondary educated.

\section{Antenatal care}

ANC is considered as one of the major indicators for pregnant women to give birth at health facility. Somali regional state has the lowest ANC service utilization (19.9\%), while the capital city (Addis Ababa) had the highest (94.2\%) utilization rate. ANC service use is 2.3 times, higher in the urban area than rural area. Educational status of mothers is also major socio-economic factor affecting utilization of ANC service. It is 3 times higher among women with more than secondary level educated than among mothers with no education. ANC service by skilled provider is $53.6 \%$ higher in the richest quantile than in the poorest quantile. On the contrary, ANC service provided by health extension workers (HEWs) is $13.1 \%$ higher in the poorest quantile than in richest quantile.

\section{Place of delivery}

Among the nine regions and two administrative cities, the Afar region had the lowest utilization (10\%) and Addis Ababa had the highest utilization (86.5\%). Women 
from urban area had 5.7 times more birth at health facility than women from rural area. Facility based delivery was 2.8 times higher in primary level educated women than those with no education. Mothers with more than secondary educational status had 4.3 times higher facility based delivery than those with primary level education. Women in the secondary level education category had 9.3 times higher facility based delivery than those with no education. Majority of the mothers (84\%) gave birth to their child at home, mainly assisted by relatives and traditional birth attendants (TBA). Some were assisted by skilled birth attendants of which majority were economically better-offs.

\section{Postnatal care}

Like that of facility-based delivery, women receiving postnatal checkup is very low. Once again, the Somali region has the lowest utilization (3.7\%), while the capital city Addis Ababa had the highest utilization (70.1\%). Women residing in the urban area had 6.4 times higher PNC uptake than those living in rural areas. Like other maternal health services discussed above PNC is also pretty much affected by maternal education. Women with more than secondary level of education had 7.4 times higher PNC uptake than mothers with no education.

In general, in addition to urban rural disparities, two key socio-economic factors were found to play a significant role for mothers to attend maternal health services (See Figs. 1 and 2). Concentration curve for the investigated reproductive and maternal health services revealed pro-rich bias (see Fig. 3). In addition, Table 3 presents results of rate-ratios and concentration indices with standard error and confidence intervals based on economic status of the women, justifying inequality in utilization of maternal health services.

\section{Discussion}

This study attempted to assess inequities in utilization of reproductive and maternal health services in Ethiopia.
Even though there were encouraging progresses in the past five years, maternal health service indicators are still alarmingly low and exhibit significant disparities between and within regions of Ethiopia.

Two developing regions in Ethiopia, Somali and Afar have the lowest level of modern contraceptive service utilization. These are also among the regions with the lowest human development index [23]. The rate of modern contraceptive methods in women at the top of wealth quantile is about two fold that of women at the bottom of wealth quantile. The computed concentration index also justifies the same finding (CI; 0.143). However, a study in Thailand [22] indicated that the rate of modern contraceptive methods among women at the bottom of wealth quantile is 1.01 times the women at the top of wealth quantile. The CI was -0.009 , which meant the services were more utilized by the poor. Another study in Cambodia indicated the rate of met needs for family planning was 1.33 times higher among the economically better-off than the poor [33].

ANC service is by far utilized by pregnant women living in urban areas than those living in rural areas, educated women than women with no education, and by richer women than poorer women. Rate of ANC service is 3.26 times, higher in women at the top quantile than in the bottom wealth quantile. The concentration index was 0.251 , which implies that the rich mainly utilize ANC service. This finding is higher than the one reported from Namibia [30], rate-ratio of 1.06 and CI of 0.0130 . Even though not considered as skilled providers, preventive and promotive health services are provided by health extension workers (HEWs). ANC is one of the services provided by HEWs. Less educated pregnant women than educated, those living in rural area than urban area and those at the bottom quantile than top quantile, mainly utilize ANC service by HEWs. It is almost the opposite of ANC provided by skilled providers (Doctors/Nurses/Midwifes). Here, the rate of ANC is 2.89 times, higher among the poor than that of the

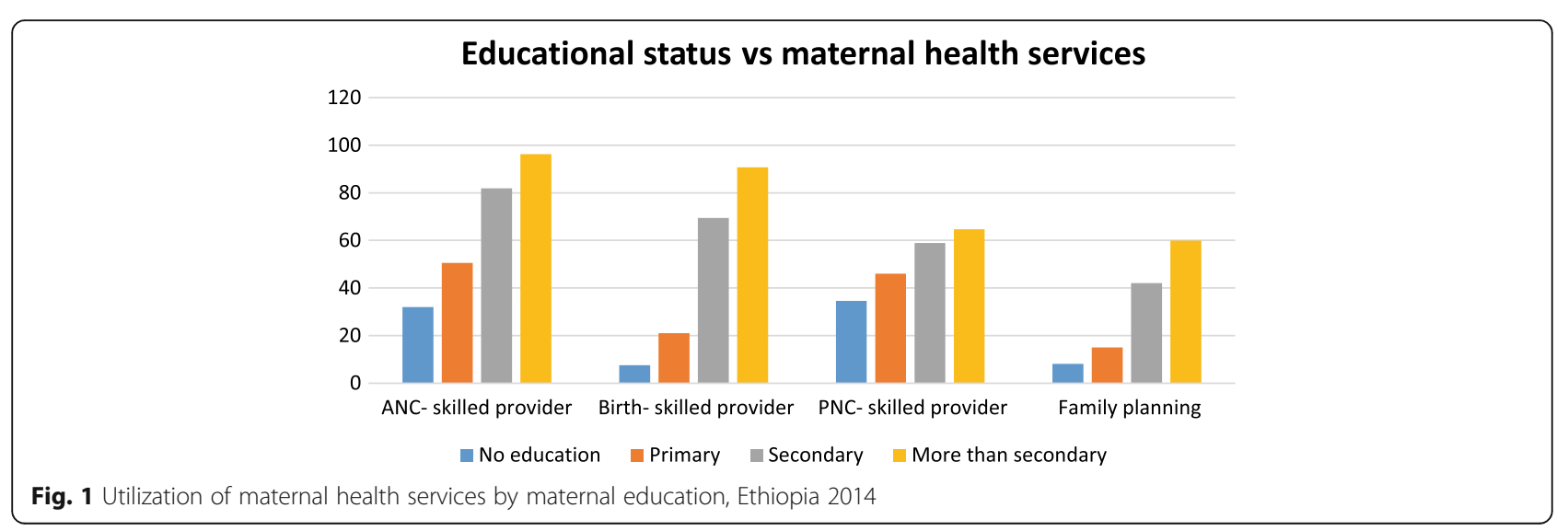




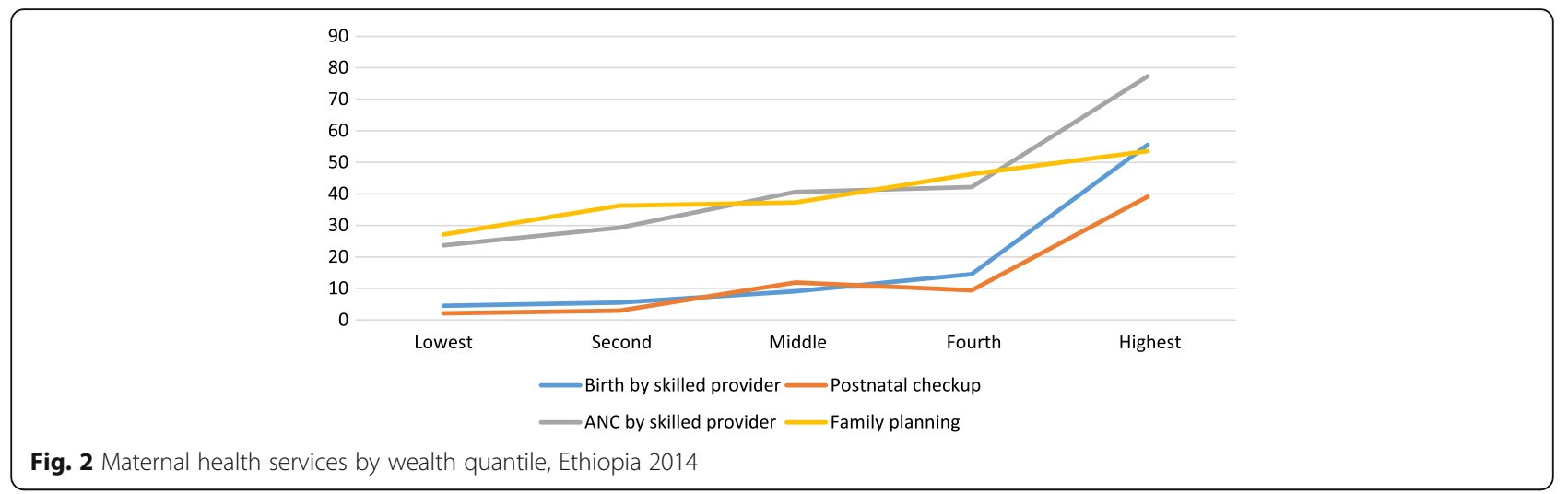

economically better-off. The $\mathrm{CI}$ is -0.135 , indicating that, the service is the mainly utilized by the poor. This could be due to the fact that HEWs are the first contact to health care system in Ethiopia especially in rural areas, where $85 \%$ the population resides [23]. HEWs are stationed closer to the population, besides working at their post they also go house to house and provide basic preventive and health promotion services [34]. As a result, they can reach part of the population who are unable to visit health centers or hospitals. Mothers at top wealth quintile have 12.3 times higher skilled provider assistance during birth than mothers at the bottom of wealth quantile. This finding is far worse than the study from Namibia where the rate is 1.63 times, higher among the rich than the poor, with CI of 0.0943 [30]. The computed CI: 0.525 also implied that the service is highly favored by the economically better off. Nowadays, many health centers are constructed in most parts of rural Ethiopia. However, urban/rural disparities continue to persist partly owing to the long distance between health facilities and residential places of the women [35]. The computed rate-ratios revealed that the uptake of birth by skilled provider is 6.4 times, higher among women living in urban areas than those living in rural areas. The government proclaims that majority of maternal health services, especially labor and delivery is free of payment, but many of the health facilities receive payments for certain aspects of the services [15].

Majority of maternal mortality occurs during postpartum period [36, 37]. While postnatal care has been proven to reduce maternal mortality during this period [38], only $13 \%$ of women received postnatal care within the first two days of delivery.

The computed CI: 0.493 revealed that the wealthy segment of the population mainly used the service. The rate of PNC in women among top wealth quantile was about 12 times that of women at the bottom of wealth quantile. When compared to other studies from Namibia [30]

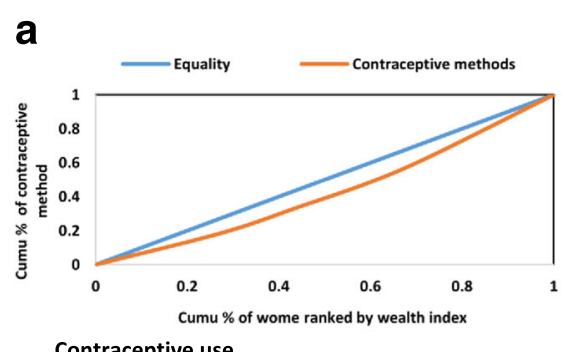

Contraceptive use

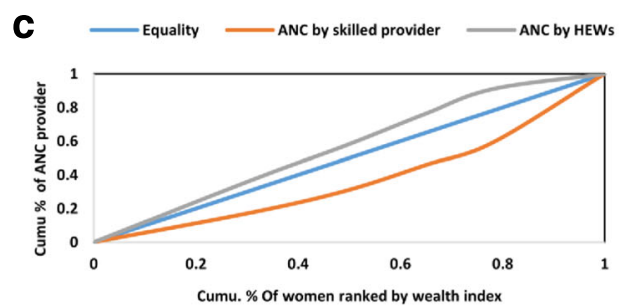

Antenatal care provider b

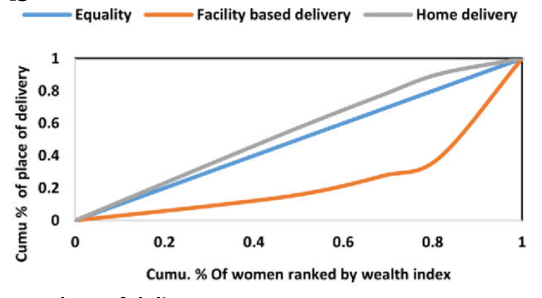

Place of delivery

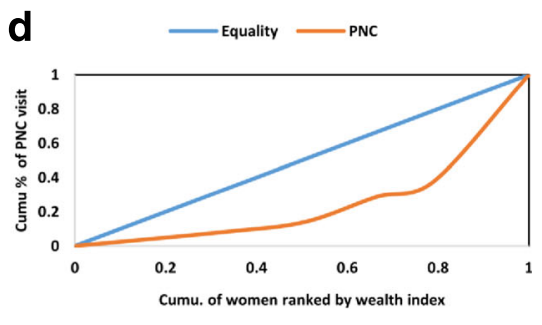

Postnatal care by skilled provider

Fig. 3 Concentration curve for indicators of reproductive and maternal health service, 2014 Ethiopia 
Table 3 Rate-ratio (rich/poor), Concentration indices standard error and confidence interval for maternal health services, Ethiopia 2014

\begin{tabular}{|c|c|c|c|c|c|}
\hline \multirow[t]{2}{*}{ Indicators } & \multirow[t]{2}{*}{ Rate-ratio (rich/poor) } & \multirow[t]{2}{*}{$\mathrm{Cl}$} & \multirow[t]{2}{*}{ Standard error } & \multicolumn{2}{|c|}{ Confidence interval (95\%) } \\
\hline & & & & Lower & Upper \\
\hline Use of modern contraceptive & 1.98 & 0.143 & 0.032 & 0.080 & 0.206 \\
\hline ANC by skilled provider & 3.26 & 0.251 & 0.29 & -0.317 & 0.819 \\
\hline Antenatal care by HEW & 0.345 & -0.135 & 0.095 & -0.321 & 0.051 \\
\hline No Antenatal care* & 0.281 & -0.195 & 0.082 & -0.356 & -0.034 \\
\hline Delivery at home & 0.45 & -0.107 & 0.065 & -0.234 & 0.020 \\
\hline Facility based delivery ${ }^{*}$ & 11.1 & 0.502 & 0.039 & 0.426 & 0.578 \\
\hline Delivery by skilled provider ${ }^{*}$ & 12.36 & 0.525 & 0.042 & 0.443 & 0.607 \\
\hline Delivery by TBA & 0.403 & -0.161 & 0.051 & -0.261 & -0.061 \\
\hline Delivery: relative/other & 0.45 & -0.072 & 0.083 & -0.235 & 0.091 \\
\hline Postnatal checkup & 11.9 & 0.493 & 0.59 & -0.663 & 1.649 \\
\hline
\end{tabular}

*Significant at $P<0.05$

with CI of 0.0835 , the finding of this study is high. This paper supports the commonly known, robust and persistent associations of social determinants of health, especially economic status and level of education with utilization of important maternal health services as stated by Ahmed et al. [4].

Educating women enhances their health- seeking behaviors, and there by improving the need to attend maternal health care services. Therefore, strengthening inter-sectoral collaboration among development sectors is crucial in order to improve maternal health and promote equity. This also means that educating women and reducing poverty, so that we can see dramatic improvements in maternal health [39]. While improving quality of services and increasing coverage are work in progress in Ethiopia, in places where health services are accessible, they often fall short of being patient-friendly.

Recently, Yesuf et al. stated that developing regions, especially Somali and Afar have the lowest birth at health facility and antenatal care utilization, which is in line with this study $[10,11]$. Possible explanation for these findings could be the poorly developed health system infrastructure and low capacity to set priorities and allocate available resources in these emerging regions of the country $[14,24]$. It is also likely that the disparity found in these regions relates to low literacy rate of the population that affects the use of available maternal health services.

Limitations the study may include, interpretation of the findings we have reported in this article should take note of the fact that the analysis in the current study is unable to reflect the current level of utilization and disparities in utilization owing to the time of data generation. Moreover, data collected on the survey were based on use of maternal health services in the past 2-5 years, which introduces the possibility of recall bias in this study.

\section{Conclusion}

Significant inequity between and within regions of Ethiopia in the use of maternal health services was demonstrated. Strategically targeting social determinants of health with special emphasis to women education and economic empowerment will significantly contribute for altering the current situation favourably. Geographical disparities in terms of regional and urban/rural differences in the use of maternal health services should be addressed by actively mobilizing the communities to raise awareness and use and making sure that the arrangements for service fit to the disadvantaged segments of the population. Finally, we recommend conducting decomposition of concentration index analysis to explain socioeconomic-related health inequalities.

\section{Abbreviations}

ANC: Antenatal care; Cl: Concentration index; DHS: Demographic and health survey; HEWs: Health extension workers; PNC: Postnatal care; TBA: Traditional birth attendance; WHO: World Health Organization

\section{Acknowledgements \\ The authors would like to thank Wollega University for providing internet and access to HINARI, WHO database of peer-reviewed Journals and Books, during manuscript preparation. All errors of omission or commission are the sole responsibility of the authors.}

\section{Funding}

Not applicable.

\section{Availability of data and materials}

Data is publically available.

Authors' contributions

FT, EA and MW conceived and designed the study, FT analyzed the data and drafted the report; FT, EA and MW contributed in the write-up and revision

of the manuscript. All authors read and approved the final manuscript.

\section{Competing interests}

The authors declare that they have no competing interests.

Consent for publication

Not applicable. 


\section{Ethics approval and consent to participate}

This study was conducted on a secondary data from 2014 Ethiopian demographic health survey. The survey was ethically cleared and the study participants were asked for their consent prior to data collection.

\section{Publisher's Note}

Springer Nature remains neutral with regard to jurisdictional claims in published maps and institutional affiliations.

\section{Author details}

'Department of Public Health, College of Health sciences; Wollega University, Nekemte, Ethiopia. ${ }^{2}$ Department of Health Economics, Management, and Policy, Faculty of Public Health; Jimma University, Jimma, Ethiopia. ${ }^{3} \mathrm{CIH}-\mathrm{LMU}$ Center for International Health, Ludwig-Maximilians-Universität München, Munich, Germany.

\section{Received: 4 November 2016 Accepted: 11 June 2017}

\section{Published online: 19 June 2017}

\section{References}

1. World Health Organization. The world health report 2010: health systems financing: the path to universal coverage, In world health report. Geneva: World Health Organization; 2010.

2. Houweling T, Ronsmans C, Campbell O, Kunst A. Huge poor-rich inequalities in maternity care: an international comparative study of maternity and child care in developing countries. Bull World Health Organ. 2007;85:745-54.

3. Culyer AJ, Wagstaff A. Equity and equality in health and health care. J Health Econ. 1993;12:431-57.

4. Ahmed S, Creanga AA, Gillespie DG, Tsui AO. Economic status, education, and empowerment: implications for maternal health service utilization in developing countries. PLoS One. 2010;5(6):e11190.

5. Alam N, Hajizadeh M, Dumont A, Fournier P. Inequalities in maternal health care utilization in Sub-saharan african countries: a multiyear and multi-country analysis. PLoS One. 2015;10(4):e0120922. doi:10.1371/journal.pone.0120922.

6. Alkenbrack S, Chaitkin M, ZengW CT, Sharma S. Did equity of reproductive and maternal health service coverage increase during the MDG Era? an analysis of trends and determinants across 74 Low- and middle-income countries. PLoS One. 2015;10(9):e0134905. doi:10.1371/journal.pone.0134905.

7. Say L, Raine R. A systematic review of inequalities in the use of maternal health care in developing countries: examining the scale of the problem and the importance of context. Bull World Health Organ. 2007;85(10):812-9.

8. Campbell OMR, Graham WJ. Strategies for reducing maternal mortality: getting on with what works. Lancet. 2006;368:1284-99.

9. Gabrysch S, Campbel O. Still too far to walk: literature review of the determinants of delivery service use. BMC Pregnancy Childbirth. 2009;9:34.

10. Yesuf EA, Kerie MW, Calderon-Margalit R. Birth in a health facility inequalities among the ethiopian women: results from repeated national surveys. PLoS One. 2014:9(4):e95439. doi:10.1371/journal.pone.0095439.

11. Yesuf EA, Calderon-Margalit R. Disparities in the use of antenatal care service in Ethiopia over a period of 15 years. BMC Pregnancy Child Birth. 2013;13:131. Available: http://www.biomedcentral.com/1471-2393/13/131.

12. Ambel, Alemayehu; Andrews, Colin; Bakilana, Anne; Foster, Elizabeth; Khan, Qaiser; Wang, Huihui. Maternal and Child Health Inequalities in Ethiopia. Policy Research Working Paper;No. 7508. World Bank, Washington, DC; 2015

13. Wabiri N, Chersich M, Zuma K, Blaauw D, Goudge J, et al. Equity in maternal health in south africa: analysis of health service access and health status in a national household survey. PLoS One. 2013;8(9):e73864. doi:10.1371/journal. pone.0073864

14. Ministry Of Health (Federal Democratic Republic of Ethiopia). Health sector transformation plan. Addis Ababa: Ministry of Health-Ethiopia; 2015.

15. Pearson L, Gandhi M, Admasu K, Keyes EB. User fees and maternity services in Ethiopia. Int J Gynaecol Obstet. 2011;115(3):310-5.

16. Ganle JK, Parker M, Fitzpatrick R, Otupiri E. Inequities in accessibility to and utilisation of maternal health services in Ghana after user-fee exemption: a descriptive study. Int J Equity Health. 2014;13(1):89

17. Simkhada B, van Teijlingen E, Porter M, Simkhada P. Factors affecting the utilization of antenatal care in developing countries: systematic review of the literature. J Adv Nurs. 2008:61(3):244-60. doi:10.1111/j.1365-2648.2007.04532.x

18. Woldemichael G, Tenorang EY. Women's autonomy and maternal health seeking behavior in Ethiopia. Matern Child Health J. 2010;14:988-98. doi:10. 1007/s10995-009-0535-5.
19. Ministry of Health (Federal Democratic Republic of Ethiopia). Health extension programme in Ethiopia. Addis Ababa: Federal Ministry of HealthEthiopia; 2007.

20. Ministry of Health (Federal Democratic Republic of Ethiopia). Health sector development program IV. Addis Ababa: Ministry of Health-Ethiopia; 2010.

21. Ministry of Health (Federal Democratic Republic of Ethiopia). Health sector strategic plan III. Addis Ababa: Ministry of Health-Ethiopia; 2009.

22. Central Statistical Agency [Ethiopia]. The 2007 population and housing census of ethiopia, Statistical summary report at national level. Addis Ababa: Central Statistical Agency; 2008.

23. United Nations Development Programme. National human development report 2014 ethiopia. Ethiopia United Nations Development Programme: Addis Ababa; 2015.

24. World Bank Group. Ethiopia Poverty Assessment 2014. World Bank, Washington, DC; 2015

25. Ethiopia Federal Ministry of Health. Ethiopia's Fifth National Health Accounts 2010/2011. Addis Ababa: Ministry of health-Ethiopia; 2014.

26. Central Statistical Agency [Ethiopia]: Ethiopia Demographic and Health Survey 2014. Addis Ababa, Ethiopia: Central Statistical Agency; August 2014

27. Schmidt E, Kedir M. Urbanization and Spatial Connectivity in Ethiopia: Urban Growth Analysis Using GIS. ESSP II Work Pap. 2009;3. Available from: http:// essp.ifpri.info/files/2011/02/ESSP2 DP03 Urbanization-and-SpatialConnectivity-in-Ethiopia.pdf

28. Barros AJ, Victora CG. Measuring coverage in $\mathrm{MNCH}$ : determining and interpreting inequalities in coverage of maternal, newborn, and child health interventions. PLoS Med. 2013;10:e1001390.

29. O'Donnell O, van Doorslaer E, Wagstaff A, Lindelow M. Analyzing Health Equity Using Household Survey Data: A Guide to Techniques and Their Implementation. World Bank.Washington, DC; 2008.

30. Zere E, Tumusiime P, Walker O, Kirigia J, Mwikisa C, Mbeeli T. Inequities in utilization of maternal health interventions in Namibia: implications for progress towards MDG 5 targets. Int J Equity Health. 2010;9:16.

31. Zere, et al. Equity in reproductive and maternal health services in Bangladesh. Int J Equity Health. 2013;12:90.

32. Zere E, Moeti M, Kirigia J, Mwase T, Kataika E. Equity in health and healthcare in Malawi: analysis of trends. BMC Publ Health. 2007;7:78

33. Dingle, et al. A decade of improvements in equity of access to reproductive and maternal health services in Cambodia, 2000-2010. Int J Equity Health. 2013;12:51.

34. Central Statistical Agency [Ethiopia] and ICF International: Ethiopia Demographic and Health Survey 2011. Addis Ababa, Ethiopia and Calverton, Maryland, USA: Central Statistical Agency and ICF International; 2012.

35. Bailey PE, Keyes EB, Parker C, Abdullah M, Kebede H, et al. Using a GIS to model interventions to strengthen the emergency referral system for maternal and newborn health in Ethiopia. Int J Gynecol Obstet. 2011;115:300-9.

36. Khan KS, Wojdyla D, Say L, Gülmezoglu AM, Van Look PFA. WHO analysis of causes of maternal death : a systematic review. Lancet. 2006;367:1066-74.

37. Ronsmans C, Graham WJ; Lancet Maternal Survival Series Steering Group. Maternal mortality: who, when, where and why. Lancet 2006;368:1189-200. doi:10.1016/S0140-6736(06)69380-X PMID:17011946

38. Shaw E, Levitt C, Wong S. Systematic Review of the Literature on Postpartum Care: Effectiveness of Postpartum Support to Improve Maternal Parenting, Mental Health, Quality of Life, and Physical Health. Birth 2006; 210-20.

39. Marmot M, Friel S, Bell R, Houweling TA, Taylor S, Commission on social determinants of health. Closing the gap in a generation: health equity through action on the social determinants of health. Lancet. 2008:372:1661?9. 